\title{
Isolation and identification of Salmonella spp. from broiler and their antibiogram study in Sylhet, Bangladesh
}

\author{
Md. Jakirul Islam ${ }^{1}$, A. T. M. Mahbub-E-Elahi ${ }^{1}$, Tanvir Ahmed ${ }^{1}$, Md. Kamrul Hasan ${ }^{2 *}$ \\ ${ }^{1}$ Department of Microbiology and Immunology, Faculty of Veterinary and Animal Science, Sylhet Agricultural University, Sylhet-3100, Bangladesh. \\ ${ }^{2}$ Department of Poultry Science, Faculty of Veterinary and Animal Science, Sylhet Agricultural University, Sylhet-3100, Bangladesh.
}

\section{ARTICLE INFO}

Article history:

Received on: 28/03/2016

Revised on: $16 / 04 / 2016$

Accepted on: $02 / 05 / 2016$

Available online: 21/06/2016

Key words:

Isolation, Identification,

Salmonella spp., Anti-

biogram study, Broiler farm.

\begin{abstract}
The objectives of this study were to isolate the associated Salmonella spp. from cloacal swabs of broiler and their antibiogram studies. A total of 80 cloacal swabs comprising of 50 samples of apparently healthy broiler and 30 samples of diarrheic broiler were collected from different poultry farms at Sylhet, Bangladesh during January to June 2013. The samples were subjected for isolation and identification of Salmonella spp. through a series of conventional bacteriological studies like study of morphology, staining properties, and biochemical characteristics. In results, $48 \%(n=24 / 50)$ swab samples of healthy broiler and $66.7 \%(n=20 / 30)$ diarrheic broiler were found to be associated with Salmonella spp. Among the 44 positive Salmonella isolates $47.73 \%(\mathrm{n}=21)$ were Salmonella pullorum, $36.36 \%(\mathrm{n}=16)$ isolates were Salmonella gallinarum and the rest $15.91 \%(\mathrm{n}=7)$ isolates were Salmonella typhimurium. Sensitivity test was conducted against 10 commonly used antibiotics, of which Penicillin-G, Erythromycin, Ampicillin, and Bacitracin were found to be resistant, and Ceftriaxone, Gentamycin, and Choloramphenicol showed considerably better sensitivity as compared to others. It is concluded that Salmonella spp. are present in broiler, and the bacteria can be clinically controlled by using Ceftriaxone, Gentamycin, and Choloramphenicol.
\end{abstract}

\section{INTRODUCTION}

Bangladesh is an agriculture based country. Poultry rearing is considered superior to the others in agricultural sector because of an almost assured in a relatively short period of time. Commercial poultry industry (mostly broiler and layer) plays an important role in the economy of Bangladesh. Little is known about the bacterial presence in the poultry environment such as in poultry litter and in the poultry house air [1]. The rural poultry production system in Bangladesh is typically a smallholder free range scavenging operation. Development of poultry sector in Bangladesh is being hampered by a number of factors, of which the diseases are considered as the major factor causing $30 \%$ mortality of chicken per year [2]. Intestinal bacteria play an important role on health through their effects on gut morphology, nutrition, pathogenesis of intestinal diseases and immune responses [3]. With the great expansion of poultry rearing and

\section{* Corresponding Author}

Md. Kamrul Hasan, Department of Poultry Science, Faculty of Veterinary and Animal Science, Sylhet Agricultural University, Sylhet3100,Bangladesh.Email:kamrul.ps@sau.ac.bd farming, Fowl typhoid caused by $S$. gallinarum is the most devastating disease in Bangladesh [4]. Important bacterial diseases of poultry in Bangladesh are Pullorum disease (PD) and Fowl Cholera (FC) which are responsible for high percentage of morbidity and mortality. Prevention of salmonella infection is important for the profitable expansion of poultry industry in Bangladesh. Salmonella infection is one of the most important bacterial diseases in poultry causing heavy economic loss through mortality and reduced production $[5,6]$. Chicks can be infected with Salmonella spp. by vertical transmission through infected parents or by horizontal transmission through hatcheries, sexing in contaminated hatcheries, cloacal infection and transportation of equipment and feed [7].

Age wise prevalence of avian Salmonellosis showed highest infection rate in adult layer $(53.25 \%)$ in comparison to brooding (14.55\%), growing (16.10\%) and pullet (16.10\%) [8]. Infections with the two non-motile serotypes Salmonella pullorum and Salmonella gallinarum which are generally host specific for avian species. Pullorum disease has great economic importance in poultry industry as it causes high mortality in young chicks, reduces growth rate in chicken and reduction of egg production in layer birds. 
Resistance against frequently used antibiotics has been observed in bacteria present in poultry since the introduction of these antimicrobial agents in poultry. The rise in antibiotic resistance has been reported in the past two decade in many countries including Bangladesh [9]. In Bangladesh, the economic aspect of poultry disease and their mortality and morbidity due to bacterial infection is a matter of great concern to the livestock owners. The antibiotic resistance pattern increases the incidence of disease in poultry and subsequently affects the economy of Bangladesh. Therefore, this study was designed to isolate and identify the Salmonella spp. from broiler and assessments of sensitivity of Salmonella spp. to different antibiotics.

\section{MATERIALS AND METHODS}

\subsection{Study area}

The sample (cloacal swab) were collected from apparently healthy and diarrheic broiler of different broiler farm located around SAU campus area (Baluchar, Alurtal, Shibgonj, Tilagore, Arambag, and Batassar) and then transported to the laboratory of the Department of Microbiology and Immunology, Sylhet Agricultural University Sylhet, Bangladesh during the period of January to June, 2013 for isolation, identification, and antimicrobial susceptibility testing.

\subsection{Collection and transportation of samples}

A total of 80 cloacal swab samples were collected and inoculated immediately into nutrient broth (NB) for better nourishment of the desirable organisms and immediately brought to Laboratory of the Department of Microbiology and Immunology, Sylhet Agricultural University Sylhet, Bangladesh.

\subsection{Cultural characterization and isolation of Salmonella spp.}

The samples were collected directly from cloaca by cotton buds and taken in nutrient broth and SSA (SalmonellaShigella Agar) plates. These were then incubated at $37^{\circ} \mathrm{C}$ for 24 hours in bacteriological incubator. After 24 hours the incubated media were then examined for growth of bacteria. Colorless or translucent colony and sometimes black color colony were observed on SS agar. The colony was then subjected to Gram's Method of staining and observed under microscope for Gram negative rods. The organisms from the agar media were subcultured into SSA, MCA (MacConkey Agar), BGA (Brilliant Green Agar), EMBA (Eosin Methylin Blue Agar), and TSIA (Triple Super Iron Agar) with the help of inoculating loop in case of Gram negative rods in the smears. In case of SSA, colorless, translucent and black colony was observed. In case of MCA, colorless and translucent colony was observed. In case of BGA, light pink colony against a rose pink background was observed. In case of EMBA, pale colony without metallic sheen was observed. In case of TSIA, a black colored colony was observed. Thus single pure colony was obtained. These pure isolates obtaining in this way were used for the further study [11]. The Salmonellae colonies were characterized morphologically using Gram's stain according to the method described by [12]. The motility test was performed to differentiate motile bacteria from non-motile one [11].

\subsection{Differentiation of isolated Salmonella spp. using biochemical test}

For this study, isolated organisms with supporting growth characteristics of Salmonella spp. were subjected to sugar (Carbohydrate) fermentation test, TSIA slant reaction, MR (Methyl red) reaction, VP (Voges-Proskauer) reaction, indole reaction and citrate utilization reaction according to the procedures as described by [11].

\subsection{Comparative antimicrobial sensitivity pattern of Salmonella spp.}

Susceptibility and resistance of different antibiotics was measured in vitro by employing the Kirby-Bauer method [13, 14]. This method allowed for the rapid determination of the efficacy of a drug by measuring the diameter of the zone of inhibition that resulted from diffusion of the agent into the medium surrounding the disc. A suspension of test organism was prepared in NB (Nutrient Broth) by overnight culture for 24 hours at $37^{\circ} \mathrm{C}$. The broth were streaked using sterile glass spreader homogenously on the medium. Antibiotic disc were applied aseptically on to the surface of the inoculated plates at an appropriate special arrangement with the help of a sterile pair of forceps on MuellerHinton agar plates. The plates were then inverted and incubated at $37^{\circ} \mathrm{C}$ for 24 hours. The diffusion discs with antimicrobial drugs were placed on the plates and incubated for 24 hours at $37^{\circ} \mathrm{C}$. The antibiotics discs (Oxoid, Basingstoke, Hampshire, England) used were: Ampicillin, Penicillin-G, Nalidixic Acid, Erythromycin, Amoxycillin, Chloramphenicol, Gentamycin, Ceftriaxone, Bacitracin and Cefalexin. Sterile glass spreader was used to spread the culture homogenously on the medium. Antibiotic disc were applied aseptically to the surface of the inoculated plates at an appropriate special arrangement with the help of a sterile pair of forceps. The plates were then inverted and incubated at $37^{\circ} \mathrm{C}$ for 24 hours. After incubation, the plates were examined and the diameters of the zone of complete inhibition were observed. Isolates were classified as susceptible, intermediate and resistant categories based on the standard interpretation table (Table 6) updated according to the Clinical and Laboratory Standards Institution [15].

\section{RESULTS AND DISCUSSION}

About 80 cloacal swabs samples were collected for the research work. Cloacal swabs have been used to provide evidence of persistent intestinal colonization by salmonellae in individual birds [16]. Among 80 cloacal swabs samples 44 samples were positive. However Salmonella spp. was isolated from 24 out of 50 apparently healthy broiler samples and 20 out of 30 diarrheic broiler samples and the average positive isolates were $48 \%$ for healthy broiler samples and $66.67 \%$ for diarrheic broiler samples 
(Table 1 and 2). The frequency distribution of Salmonella spp. isolates in different farm samples were found variable. However, each of the positive samples was treated as an isolate. Among the 80 samples tested from the apparently healthy and diarrheic birds in the broiler farms Salmonella spp. could be isolated from 44 $(55 \%)$ samples which were in close agreement with [17]. The highest average infection rate $(66.67 \%)$ was isolated from diarrheic broiler than the apparently healthy broiler (48\%). So, the rate of isolation was higher than the findings of [18].

During the isolation, identification of bacterial colonies having typical cultural characteristics was selected as presumptive for Salmonella serovers. For this, general purpose and differential selective media such as SSA, BGA, TSIA and EMBA were used to culture the organism although all of them are not found equally suitable for all the serovars of Salmonella (Table 3). In the present study, specific enriched media and biochemical tests mentioned above were also used by a number of researchers [19, 20, 21, 22, 23]. The colony characteristics of Salmonella spp. such as translucent, black or colorless, smooth, small round colonies on SSA; black colored colonies on TSI agar were similar to the findings of other authors [19, 20, 21, 24, 25]. In Gram's staining, the morphology of the isolated salmonellae exhibited Gram negative characteristics of small rod shaped, single or paired in arrangement under microscope was reported by other researchers $[11,26]$. Motility test was fundamental basis for the detection of motility or otherwise characteristics of Salmonella organisms [20, $21,26]$. In carbohydrate fermentation test, the isolates that fermented glucose, maltose and produced acid and gas but did not ferment lactose those indicated positive for Salmonellae as was stated by [20]. Among the 44 positive Salmonella isolates, $47.73 \%$ (where $\mathrm{n}=21$ ) fermented glucose, maltose, rhamnose and produced both acid and gas but did not ferment dulcitol was considered positive for $S$. pullorumum. Only $36.36 \%$ isolates (where $n=16$ ) fermented glucose, maltose, dulcitol without producing acid and gas and did not ferment rhamnose indicating typical characteristics of $S$. gallinarum. The rest $15.91 \%$ isolates $(n=7)$ fermented glucose, maltose, rhamnose and dulcitol with or without gas demonstrated provided indication of being S. typhimurium (Table $5)$. These observations are strongly correlated with the theme of [23, 24, 27]. A total of 44 (where $n=44$ ) isolates were positive for Methyl Red test but negative for VP test indicating characteristics of Salmonella spp. test which was similar with the statement of [25]. In indole test, all the test isolates (where $n=44$ ) did not develop any red color that indicated the Salmonella isolates were negative to indole test and this was similar with the findings of [23]. Organisms isolated from the collected samples under test, revealed unequivocal morphological, cultural and biochemical properties resembling Salmonella spp. as was recorded by [19, 20, $21,26]$.

Among the 44 isolates (where $n=44$ ) of 21 isolates were similar to Salmonella pullorum and only 16 isolates showed the characteristics of Salmonella gallinarum and 7 isolates were more or less similar to Salmonella typhimurium. The study also indicated that the field sample contained Gram negative, rod shape and motile organism with various colony characteristics (large, smooth, round and sticky) in different bacteriological media. The isolates was able to produce characteristic black metallic sheen colonies on EMBA, pink colony on, pinkish colony on SSA.

Table 1: Isolation of Salmonella spp. from cloacal swab collected from broiler farms (apparently healthy broiler).

\begin{tabular}{|c|c|c|c|c|}
\hline Sl. No. & Name of farms and Location & $\begin{array}{c}\text { No. of samples } \\
\text { collected }\end{array}$ & $\begin{array}{c}\text { No. of samples positive for } \\
\text { Salmonella spp. }\end{array}$ & $\begin{array}{c}\text { Positive } \\
\text { samples }(\%)\end{array}$ \\
\hline $\mathrm{F}_{1} \mathrm{H}_{10} \mathrm{~B}$ & Baluchar Poultry Farm, Baluchar, Sonarbangla, Sylhet, Bangladesh & 10 & 4 & 40 \\
\hline $\mathrm{F}_{2} \mathrm{H}_{14} \mathrm{~B}$ & Lui Poultry Farm, Alurtal, Sylhet, Bangladesh & 14 & 6 & 42.85 \\
\hline $\mathrm{F}_{3} \mathrm{H}_{16} \mathrm{~B}$ & Delwar Broiler Farm, Mijortilla, Islampur, Sylhet, Bangladesh & 16 & 9 & 56.25 \\
\hline \multirow[t]{2}{*}{$\mathrm{F}_{4} \mathrm{H}_{10} \mathrm{~B}$} & Bhi-Bon Poultry farm, Bagmara, Sylhet, Bangladesh & 10 & 5 & 50 \\
\hline & & Total $=50$ & Total $=24$ & Av. $=48 \%$ \\
\hline
\end{tabular}

Table 2: Isolation of Salmonella spp. from cloacal swab collected from broiler farms (diarrheic broiler).

\begin{tabular}{|c|c|c|c|c|c|}
\hline Sl. No. & Name of farms and Location & $\begin{array}{c}\text { No. of } \\
\text { diarrheic } \\
\text { birds }\end{array}$ & $\begin{array}{l}\text { No. of sample } \\
\text { collected }\end{array}$ & $\begin{array}{l}\text { No. of samples positive } \\
\text { for Salmonella spp. }\end{array}$ & $\begin{array}{c}\text { Positive } \\
\text { samples }(\%)\end{array}$ \\
\hline$\overline{F_{1} D_{10} B}$ & Al-manar Broiler Farm, Shaplabag, Tilagore, Sylhet, Bangladesh & 85 & 10 & 8 & 80 \\
\hline $\mathrm{F}_{2} \mathrm{D}_{5} \mathrm{~B}$ & 3-star Poultry Farm, Gailapara, Batassar, Sylhet, Bangladesh & 50 & 5 & 3 & 60 \\
\hline $\mathrm{F}_{3} \mathrm{D}_{10} \mathrm{~B}$ & Chawdari Poultry Farm, Batassar, Sylhet, Bangladesh & 107 & 10 & 7 & 70 \\
\hline \multirow[t]{2}{*}{$\mathrm{F}_{4} \mathrm{D}_{5} \mathrm{~B}$} & Alurtal Poultry Farm, Alurtal, Sylhe, Bangladesh & 70 & 5 & 2 & 40 \\
\hline & & & Total $=30$ & Total $=20$ & $\mathrm{Av} .=66.7 \%$ \\
\hline
\end{tabular}

FDB: Farms of diarrheic birds, Av.: Average.

Table 3: Result of Growth cultural and morphological characteristics of Salmonella spp.

\begin{tabular}{|c|c|c|c|c|c|c|}
\hline \multicolumn{5}{|c|}{ Colony characteristics } & \multirow{2}{*}{$\begin{array}{c}\text { Staining } \\
\text { - characteristics }\end{array}$} & \multirow{2}{*}{$\begin{array}{c}\text { Motility } \\
\text { (Hanging drop method) }\end{array}$} \\
\hline BGA & $\begin{array}{r}\text { SSA } \\
\end{array}$ & $\mathrm{MCA}$ & TSIA & EMBA & & \\
\hline $\begin{array}{l}\text { Pale, colorless } \\
\text { against a pinkish } \\
\text { background }\end{array}$ & $\begin{array}{l}\text { Opaque, translucent, } \\
\text { colorless, smooth, round } \\
\text { with black center. }\end{array}$ & $\begin{array}{l}\text { Pale, colorless, smooth, } \\
\text { transparent, raised } \\
\text { colonies }\end{array}$ & $\begin{array}{l}\text { Black colored } \\
\text { colony }\end{array}$ & $\begin{array}{l}\text { Pale colonies } \\
\text { without } \\
\text { Metallic sheen }\end{array}$ & $\begin{array}{l}\text { Pink short rod, } \\
\text { gram negative } \\
\text { bacilli }\end{array}$ & $\begin{array}{l}+\mathrm{Ve}(S . \text { typhimurium }) \\
-\mathrm{Ve}(S . \text { pullorum, } S . \text { gallinarum })\end{array}$ \\
\hline
\end{tabular}

Here, BGA = Brilliant Green Agar, SSA = Salmonella-Shigella Agar, MCA = MacConkey Agar, TSIA = Triple Super Iron Agar, EMBA = Eosin Methylin Blue Agar, $+=$ Positive, $-=$ Negative. 
Table 4: Result of biochemical characteristics of Salmonella spp.

\begin{tabular}{|c|c|c|c|c|c|c|c|c|}
\hline \multirow{2}{*}{$\begin{array}{c}\text { Indole } \\
\text { Test }\end{array}$} & \multirow{2}{*}{$\begin{array}{l}M R \\
\text { test }\end{array}$} & \multirow{2}{*}{$\begin{array}{c}P P \\
\text { test }\end{array}$} & \multicolumn{5}{|c|}{ Sugar fermentation test } & \multirow[t]{2}{*}{ Citrate Utilization test } \\
\hline & & & Dextrose & Sucrose & Lactose & Maltose & Mannitol & \\
\hline- & + & - & + & - & - & + & + & + \\
\hline
\end{tabular}

Here, MR = Methyl red, VP = Voges-Proskauer, $+=$ positive reaction, - = negative reaction .

Table 5: Results of percentage (\%) of Salmonella spp. available in cloacal swab.

\begin{tabular}{|c|c|c|}
\hline \multirow{2}{*}{ Name of organism } & \multicolumn{2}{|c|}{ Percentage $(\%)$ of Salmonella spp. available in cloacal swab } \\
\hline & Cloacal swab (from apparently healthy broiler) & Cloacal swab (from diarrheic broiler) \\
\hline Salmonella pullorum (21) & $10(46.62 \%)$ & $11(52.38 \%)$ \\
\hline Salmonella gallinarum (16) & $9(56.25 \%)$ & $7(43.75 \%)$ \\
\hline Salmonella typhimurium (7) & $5(71.43 \%)$ & $2(28.57 \%)$ \\
\hline Total $=44$ & 24 & 20 \\
\hline
\end{tabular}

Table 6: Interpretive standards for disc diffusion susceptibility testing.

\begin{tabular}{|c|c|c|c|c|}
\hline \multirow{2}{*}{ Name of Antibiotic disc } & \multirow{2}{*}{ Disc concentration } & \multicolumn{3}{|c|}{ Diameter of zone of Inhibition (mm) } \\
\hline & & Sensitive & Intermediate & Resistant \\
\hline Ceftriaxone & $30 \mu \mathrm{g}$ & $\geq 21$ & $14-20$ & $\leq 13$ \\
\hline Gentamycin & $10 \mu \mathrm{g}$ & $\geq 15$ & $13-14$ & $\leq 12$ \\
\hline Choloramphanicol & $30 \mu \mathrm{g}$ & $\geq 18$ & $13-17$ & $\leq 12$ \\
\hline Cephalexin & $30 \mu \mathrm{g}$ & $\geq 18$ & $15-17$ & $\leq 14$ \\
\hline Amoxycillin & $20 \mu \mathrm{g}$ & $\geq 18$ & $14-17$ & $\leq 13$ \\
\hline Erythromycin & $15 \mu \mathrm{g}$ & $\geq 23$ & $14-22$ & $\leq 13$ \\
\hline Ampicillin & $10 \mu \mathrm{g}$ & $\geq 17$ & $14-16$ & $\leq 13$ \\
\hline Nalidixic acid & $30 \mu \mathrm{g}$ & $\geq 19$ & $14-18$ & $\leq 13$ \\
\hline
\end{tabular}

$\mu \mathrm{g}=$ micro gram, $\mathrm{mm}=$ millimeter.

Table 7: Results of inhibitory zone in 6 samples with 10 antibiotics.

\begin{tabular}{|c|c|c|c|c|c|c|c|c|c|}
\hline \multirow{3}{*}{ Antibacterial agents } & \multicolumn{6}{|c|}{ Zone of inhibition (mm) } & \multirow{3}{*}{$\begin{array}{c}\text { Average } \\
(\mathbf{m m})\end{array}$} & \multirow{3}{*}{ Remarks } & \multirow{3}{*}{$\begin{array}{l}\text { Choice of } \\
\text { drug }\end{array}$} \\
\hline & \multicolumn{6}{|c|}{ Sample number } & & & \\
\hline & 1 & 2 & 3 & 4 & 5 & 6 & & & \\
\hline Ceftriaxone & 35.8 & 36 & 36 & 36.2 & 36 & 35.6 & 35.93 & Sensitive & $1^{\text {st }}$ \\
\hline Gentamycin & 28.8 & 30.5 & 27.5 & 35 & 29 & 32 & 30.46 & Sensitive & $2^{\text {nd }}$ \\
\hline Choloramphanicol & 28.5 & 31 & 30 & 25.5 & 30 & 29.60 & 29.1 & Sensitive & $3^{\text {rd }}$ \\
\hline Cefalexin & 21.5 & 17.5 & 18.3 & 20 & 19.1 & 20 & 19.4 & Sensitive & $5^{\text {th }}$ \\
\hline Amoxycillin & 19 & 23.2 & 18 & 15.8 & 21.9 & 17.5 & 18.9 & Sensitive & $6^{\text {th }}$ \\
\hline Erythromycin & - & - & - & - & - & - & - & Resistant & - \\
\hline Ampicillin & - & - & - & - & - & - & - & Resistant & - \\
\hline Penicillin & - & - & - & - & - & - & - & Resistant & - \\
\hline Nalidixic acid & 18.7 & 21.5 & 17.5 & 20 & 17.7 & 19.5 & 22.15 & Sensitive & $4^{\text {th }}$ \\
\hline Bacitracin & - & - & - & - & - & - & - & Resistant & - \\
\hline
\end{tabular}

$\mathrm{mm}=$ millimeter.

The antibiotic sensitivity test against the Salmonellosis with commonly used 10 antibiotics such as Nalidixic Acid, Penicillin-G, Erythromycin, Ampicillin, Ceftriaxone, Gentamycin, Bacitracin, Cefalexin, Amoxycillin, and Chloramphenicol. The result of the inhibition of the bacterial growth was variable in different antibiotics (Table 7). Multidrug resistance was detected in case of apparently healthy bird's samples and diarrheic bird's samples. The results showed that out of 10 antibiotics, 4 antibiotics (Penicillin-G, Erythromycin, Ampicillin and Bacitracin) were resistant. Salmonella resistance to penicillin has also been reported by [28]. The present findings where Salmonella spp. resistant to erythromycin supported by [28, 29, 30, 31]. Salmonella spp. resistant to Ampicillin supported by [32]. Several strains of multiple antimicrobial resistant Salmonella spp. in chicken reported by [33]. Remaining 6 antibiotics were sensitive in which Ceftriaxone showed highest inhibitory zone about $35.93 \mathrm{~mm}$ in average of 6 samples. Gentamycin showed 2nd highest inhibitory zone about $30.46 \mathrm{~mm}$ in average of 6 samples. Choloramphanicol showed 3rd highest inhibitory zone about $29.1 \mathrm{~mm}$ in average of 6 samples. These findings were more close to the previous result of
[34]. The result of present findings where Salmonella spp. sensitive to Gentamycin supported by [29, 32, 35, 36, 37]. This result were similar to previous findings where Salmonella spp. sensitive to Chloramphenicol supported by [30, 31, 37, 38, 39]. The result of this test provided the guideline for the veterinarian to select appropriate antibiotics to reduce the economic loss through selecting the sensitive antibiotics for Salmonellosis which have public health significance.

\section{CONCLUSION}

Salmonella spp. were isolated and characterized successfully from broiler using different cultural, morphological examination, biochemical and antimicrobial susceptibility tests. The findings of the present study revealed the presence of multidrug resistant Salmonella spp. in broilers at Sylhet district of Bangladesh. There might be variation in strains of Salmonella spp. So, the genetic variation leading to highly resistant Salmonella spp. to constitute a threat for poultry industry in Bangladesh and also the findings of the experiment speculate that the use of 
Ceftriaxone, Gentamycin, and choloramphanicol might have the preference in clinical control of Salmonellosis. Further studies calling for attention for future research might be molecular characterization and genomic studies to have an idea about genes responsible for pathogenecity and drug resistance of the isolates of Salmonellae from cloacal swab of broiler.

\section{REFERENCES}

1. Saleh M, Seedorf J, Hartung J. Total count of bacteria in the air of three different laying hen housing systems. Dtsch Tierarztl Wochenschr. 2003; 110:94-97.

2. Das PM, Rajib DMM, Noor M, Islam MR. Relationship analysis on the proportional incidence of poultry disease in greater Mymensingh of Bangladesh. In: Proceeding of the 4th International Poultry Show \& Seminar organized by World's Poultry Science Association, Bangladesh Branch. 2005; pp.35-39.

3. Mead GC. Prospects for competitive exclusion treatment to control Salmonella and other food home pathogen in poultry. Veterinary Journal. 2000; 159:111-123.

4. Begum F, Khan MSR, Chowdhury KA, Rahman MM, Amin MM. Studies on immune response of chickens to fowl typhoid vaccine. Bangladesh Journal Microbiology. 1993; 10:51-56.

5. Haider MG, Hossain MG, Hossain MS, Chowdhury EH, Das PM, Hossain MM. Isolation and characterization of Enterobacteria Associated with Health and Disease in Sonali Chickens. Banganladesh Journal of Veterinary Medicine. 2004; 2(1):15-21.

6. Talha AFSM, Hossain MM, Chowdhury EH, Bari ASM, Islam MR, Das PM. Poultry diseases occurring in Mymensingh district of Bangladesh. The Bangladesh Veterinarian. 2001; 18:20-23.

7. Opitz HM, El-Begearmi M, Flegg P, Beane D. Effectiveness of five feed additives in chicks infected with Salmonella enteritidis phage type 13A. Poultry Research. 1993; 2:147-153.

8. Rahman H, Kumar A, Murugkar HV, Bhattacharyya DK, Shome BR, Shome R. Some epidemiological features of Salmonella typhimurium isolates from north east India. Indian Journal of Animal Sciences. 2004; 74(6):609-611.

9. Kapil A. The challenge of antimicrobial resistance: need to contemplate. Indian Journal of Medical Research. 2004; 121:83-91.

10. Carter GR, John R Cole Jr. Diagnostic procedure in Veterinary bacteriology and Mycology. 1985; pp.551-552, 556.

11. Cheesbrough M. Medical laboratory manual for tropical countries. Vol. 2. Microbiology. 1985; pp.400-480.

12. Merchant IA, Packer RA. Veterinary bacteriology and virology, 7th edn. The Iowa University Press, Ames, Iowa, USA. 1967; 286-306.

13. Bauer AW, Kirby WM, Sherris JC. Antibiotic susceptibility testing by a standard single disc method. American Journal of Clinical Pathology. 1966; 45:493-496.

14. Jakaria ATM, Islam MA, Khatun MM. Prevalence, characteristics and antibiogram profiles of Escherichia coli isolated from apparently healthy chickens in Mymensingh, Bangladesh. Microbes Health. 2012; 1:27-29.

15. Clinical and Laboratory Standards Institute. Performance standards for antimicrobial susceptibility testing; 21th informational supplement. CLSI document M100-S21. Clinical and Laboratory standards Institute. Wayne, pa. 2011; pp.114-117.

16. Gast RK. Paratyphoid Infections. In Diseases of Poultry, 10th ed; Calnek BW, Barnes HJ, Beard CW, McDoughald LR, Saif YM, Eds. Iowa State University press: Ames, IA, USA. 1997; pp.97-121.

17. Ahmed AKM, Islam MT, Haider MG, Hossain MM. Sero prevalence and pathology of naturally infected Salmonellosis in poultry with isolation and identification of causal agents. Journal of the Bangladesh Agricultural University. 2008; 6(2):327-334.

18. Hossain MA, Aalbaek B, Christensen JP, Elisabeth H, Islam MA, Pankaj K. Observations on experimental infection of Salmonella gallinarum in Fayoumi and Hyline layer chickens. Bangladesh Journal of Progressive Agriculture. 2006; 14:85-89.
19. Amin MM. Isolation and identification of Salmonella from wild birds, rodents and insects. M.S. thesis, Department of Microbiology and Hygiene, Faculty of Veterinary Sciences, Bangladesh Agricultural University, Mymensingh. 1969; pp.1-48.

20. Buxton A, Fraser G. Animal Microbiology Vol. 1. Blackwell Scientific Publications, Oxford, London, Edinburg, Melbourne. 1977; pp.93-157.

21. Hossain KM. Characterisation of bacteria isolated from diarrheic calves. M.S Thesis, Department of Microbiology and Hygiene. Faculty of Veterinary Science, Bangladesh Agricultural University, Mymensingh. 2002; pp.1-72.

22. Habrun B, Mitak M. Monitoring for faecal Salmonella spp. in poultry. Zagreb, Croatia: Croatian Veterinary Institute, Poultry Centre. Hrvatska. 2003; pp.161-163.

23. Lee TJ, Kim KS, Kwon YK, Kang MS, Mo IP, Kim JH, Tak RB. Prevalent characteristics of fowl typhoid in Korea. Journal of Veterinary Clinical Pathology. 2003; 20:155-158.

24. Sujatha K, Dhanalakshmi K, Rao AS. Isolation and characterization of Salmonella gallinarum from chicken. Indian Veterinary Journal. 2003; 80:473-474.

25. Muktaruzzaman M, Haider MG, Ahmed AKM, Alam KJ, Rahman MM, Khatun MB, Rahman MH, Hossain MM. Validation and refinement of Salmonella pullorum (SP) colored antigen for diagnosis of Salmonella infections in the field. International Journal Poultry Science. 2010; 9:801-808.

26. Freeman BA. Burrows Textbook of Microbiology. 22th edn. In: W. B. Saunders Company, Philadelphia, London, Toronto, Mexico City, Rio de Janerio, Sydney, Tokyo. 1985; pp.464-475.

27. Kwon YK, Kim A, Kang MS, Her M, Jung BY, Lee KM, Jeong W, Kwon JH. Prevalence and characterization of Salmonella gallinarum in the chicken in Korea during 2000 to 2008. Poultry Science. 2010; 89:36-42.

28. Sultana K, Bushra MA, Nafisa I. Evaluation of antibiotic resistance in clinical isolates of Salmonella typhi from Islamabad. Pakistan Journal of Zoology. 1992; 27:185-187.

29. Ferdous TA, Kabir SML, Amin MM, Hossain KMM. Identification and Antimicrobial Susceptibility of Salmonella species isolated from washing and rinsed water of Broilers in pluck shops. International Journal of Animal and Veterinary Advances. 2013; 5(1):1-8.

30. Roy SR, Rahman MB, Hassan J, Nazir KHMNH. Isolation and identification of bacterial flora from internal organs of Broiler and their antibiogram studies. Microbes and Health. 2012; 1(2):72-75.

31. Khan MFR, Rahman MB, Khan MSR, Nazir KHMNH, Rahman M. Antibiogram and plasmid profile analysis of isolated Poultry Salmonella of Bangladesh. Pakistan journal of biological Science, 2005; 8(11):1614-1619.

32. Saifullah MK, Mamun MM, Rubayet RM, Nazir KHMNH, Zesmin K, Rahman MT. Molecular detection of Salmonella spp. isolated from apparently healthy pigeon in Mymensingh, Bangladesh and their antibiotic resistance pattern. Journal of Advanced Veterinary and Animal Research. 2016; 3(1):51-55.

33. Manie T, Khan S, Veith W, Bro"Zel VS, Gouws PA. 1998. Antimicrobial resistance of bacteria isolated from slaughtered and retail chicken in South Africa. Letters in Applied Microbiology. 1998; 26:253-258.

34. Banani M, Pourbakash SA, Khaki P, Nikookhesal GH. Serotyping and drug sensitivity of Salmonella isolates from commercial chicken and domestic pigeons submitted to Razi institute. Pajouhesh-va-sadandegiin-Animal-Science. 2003; 59:92-96.

35. Shah AH, Korejo NA. Antimicrobial resistance profile of Salmonella serovars isolated from chicken meat. Journal of Veterinary and Animal Science. 2012; 2:40-46.

36. Kabir SML. Avian colibacillosis and salmonellosis: A closer look at epidemiology, pathogenesis, diagnosis, control and public health concerns. International Journal of Environmental Research and Public Health. 2010; 7:89-114.

37. Jahan F, Kabir SML, Amin MM. Identification and antimicrobial resistance profiles of Salmonellae isolated from the broiler dressing 
plants associated with their environments. Advanced Research Journal of Microbiology. 2013; 1(1):1-9.

38. De-Jong A, Thomas V, Simjee S, Godinho K, Schiessl B, Klein U, Butty P, Valle M, Marion H, Shryock TR. Pan- European monitoring of susceptibility to human use antimicrobial agents in enteric bacteria isolated from healthy food producing animals. Journal of Antimicrobial Chemotherapy. 2012; 67:638-51.

39. Khan MFR, Rahman MB, Sarker SK. Seroprevalence of Mycoplasma gallisepticum infection in poultry in some selected farms of Mymensingh. Journal of The Bangladesh Society for Agricultural Science and Technology. 2005; 2:1-4.

\section{How to cite this article:}

Islam MJ, Mahbub-E-Elahi ATM, Ahmed T, Hasan MK. Isolation and identification of Salmonella spp. from broiler and their antibiogram study in Sylhet, Bangladesh. J App Biol Biotech. 2016; 4 (03): 046-051. DOI: 10.7324/JABB.2016.40308 